\title{
Practice of New Normal Lifestyles, Economic and Social Disruption, and Level of Happiness Among General Public in China in the Post-COVID-19 Era
}

\author{
Xu Lin \\ Yulan Lin $^{2}$ \\ Zhijian $\mathrm{Hu}^{2}$ \\ Haridah Alias ${ }^{3}$ \\ Li Ping Wong $\mathbb{D}^{2,3}$ \\ 'Department of Respiratory and Critical \\ Care Medicine, Fuzhou Pulmonary \\ Hospital of Fujian, Educational Hospital of \\ Fujian Medical University, Fuzhou, \\ 350004, Fujian, People's Republic of \\ China; ${ }^{2}$ Department of Epidemiology and \\ Health Statistics, School of Public Health, \\ Fujian Medical University, Fuzhou, \\ 350 122, Fujian, People's Republic of \\ China; ${ }^{3}$ Centre for Epidemiology and \\ Evidence-Based Practice, Department of \\ Social and Preventive Medicine, Faculty of \\ Medicine, University of Malaya, Kuala \\ Lumpur, 50603, Malaysia
}

Purpose: This study aimed to investigate the impact of the COVID-19 pandemic on the practice of 'new normal' lifestyles, economic and social distribution, and individuals' wellbeing of people in China after the country ease the lockdown restriction.

Methods: A cross-sectional, self-administered online survey was carried out between 3 September and 15 October 2020.

Results: A total of 8393 complete responses were received from a nationwide sample. Poor sustainability in the practice of "new norm" was reported. Noteworthy disparities were observed in willingness to carry out "new normal" practices by gender, urban-rural locality, non-Han and Han Chinese and educational attainment. There was evidence of economic and social disruption associated with COVID-19 or "new normal" practices. The current mean ( \pm standard deviation $[\mathrm{SD}])$ happiness score $(110.45 \pm 17.55)$ was slightly lower than the mean happiness score before $(111.12 \pm 17.83)$ the COVID-19 pandemic $(\mathrm{t}=-9.01, \mathrm{p}<0.001)$. Lower socioeconomic status and greater economic and social disruptions were associated with lower current happiness scores. Moreover, greater willingness to adapt to "new normal" practices was associated with higher levels of happiness.

Conclusion: There is a need to encourage sustainable practice of new norm post-pandemic. Segments of the public continue to experience significant economic and social effects and the post-pandemic 'new norms' remain at risk of leading to psychological consequences.

Keywords: new-normal, COVID-19, happiness index

\section{Introduction}

Coronavirus (COVID-19) continues to spread rapidly worldwide and has become a large-scale pandemic. This outbreak has not only led to a dramatic loss of human life, but has also resulted in profound impacts on many aspects of general public life and the economy. To curb the disease's spread, many countries around the world have implemented unprecedented measures, such as quarantines to reduce interactions between individuals, travel restrictions and closures of schools and businesses. The negative social and economic impacts of preventive measures against the coronavirus have tremendously influenced the general public's well-being. One study has reported the physiological and psychological impacts of wearing face masks during the COVID19 pandemic. $^{1}$ The consequences of physical and social distancing on people's psychological state have also been reported worldwide, ${ }^{1-3}$ including in China. ${ }^{4}$

In early April 2020, China successfully emerged from the first wave of the COVID19 pandemic and social activities gradually resumed. ${ }^{5}$ In many countries around the
Correspondence: Yulan Lin Email yulanlin@fjmu.edu.cn

Li Ping Wong

Email wonglp@ummc.edu.my 
world, the continued adoption of infection-prevention practices as part of a "new normal" way of life has been encouraged to minimise transmission and prevent a second wave. In China, maintaining physical and social distancing, wearing a protective face mask, undergoing temperature checks, inquiring into people's recent travel history, writing down one's name and identification number and scanning a Quick Response (QR) code are among the strategies and practices implemented for a post-COVID-19 recovery. Sustainability in COVID-19 prevention measures is important, nonetheless, in China, the level of willingness in carrying out "new normal" practices is unknown. Identifying "new normal" practice gaps is essential to help in the development of interventions to enhance support in post-pandemic new normal lifestyles.

The well-being of the public in the post-COVID-19 recovery has not been extensively investigated. Compared to before the pandemic, a decrease in emotional well-being and happiness among the public in China has been reported. ${ }^{6}$ Another study has reported greater satisfaction and decreasing depressive symptoms after the lockdown was lifted in Wuhan. ${ }^{7}$ Nevertheless, the perspectives towards and the psychological responses of adjusting to a "new normal" lifestyle post-COVID-19 in China have received little attention. The global response to the pandemic has led to unexpected changes in people's daily lifestyles. It is unclear whether continuous restrictions and lifestyle adjustments will trigger unease among the public, especially after months of strict lockdown restrictions during the early onset of the pandemic.

This study aimed to investigate the impact of the COVID-19 pandemic on the practice of new normal lifestyles, economic and social disruption and individuals' psychological well-being of people in China in the postCOVID-19. The psychological well-being before the COVID-19 pandemic was also assessed (using retrospective recall). The psychological well-being comparing before the COVID-19 pandemic was then investigated. Examining the differences in psychological well-being before and after the pandemic will provide important information into potential psychological vulnerability and the pandemic's psychological impact.

\section{Materials and Methods Study Participants and Survey Design}

We carried out a cross-sectional, web-based survey using an online questionnaire between 3 September and 15 October 2020. Figure 1 shows the study's data collection period and the trend of confirmed COVID-19 cases in China. The inclusion criteria were that the respondents were citizens of China and aged between 18 and 70 years old. We used the social network WeChat (the most popular messaging app in China) to advertise and circulate the survey link to the general public in all provinces across mainland China. The participants were informed that their participation was voluntary; consent was implied through their completion of the questionnaire. The participants were enumerated upon completion of the survey.

China's main economic regions are divided into North, Northeast, East, South central, Southwest and Northwest regions. The sample size was calculated for each region using the equation: $n=Z^{2} p(1-p) / d^{2}$. Using a margin of error of $0.05(5 \%)$, with a $95 \%$ CI and $50 \%$ response distribution, the calculated sample size was 384 . The sample size was multiplied by the predicted design effect of

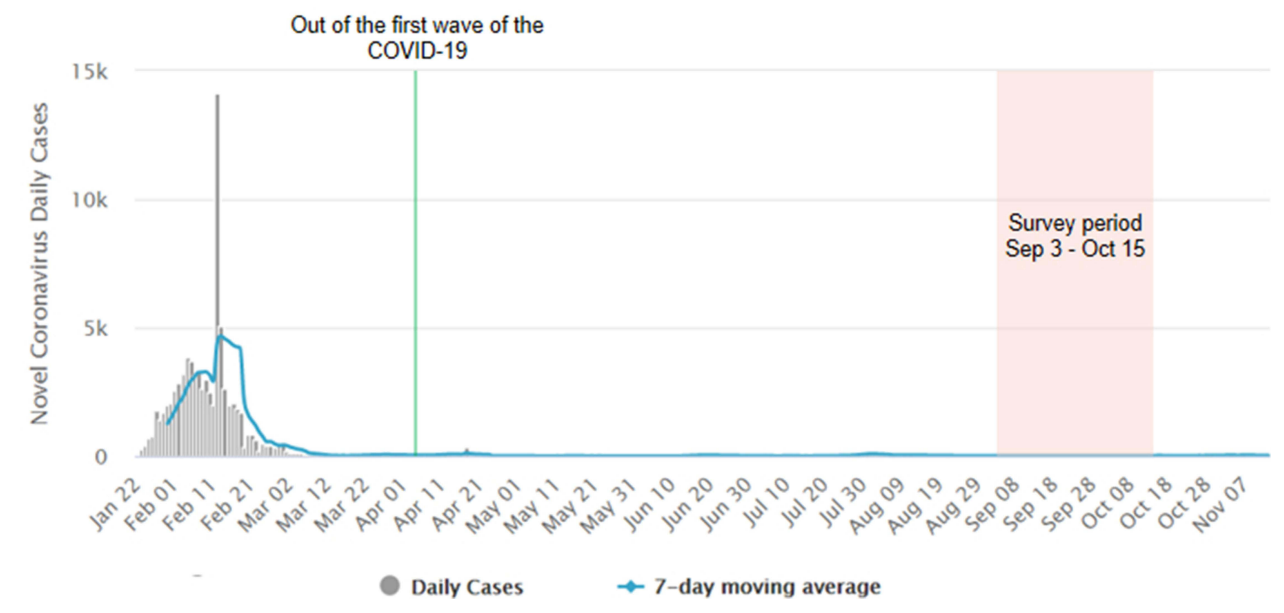

Figure I Data collection period of the study and the trend of confirmed cases of COVID-19 in China. 
two to account for the use of convenience sampling and an online survey. Hence, the minimum survey sample size for each region was set to 768 (384 x 2) participants.

\section{Instruments}

The questionnaire was developed in English and subsequently translated into Chinese. Independent experts reviewed and validated the translation, after which it was pilot-tested. The survey questions consisted of four sections, assessing i) demographic background, ii) willingness to carry out "new normal" practices, iii) economic and social disruption associated with COVID-19 and iv) psychological well-being, using the Chinese version of the Oxford Happiness Questionnaire. Participants rated their current level of 1) "new normal" practices, 2) economic and social disruption, and 3) psychological well-being during the survey period. The assessment of psychological well-being before the COVID-19 pandemic was carried out using retrospective recall method.

\section{Demographics}

The participants were asked for their personal details, including age, gender, ethnicity, educational level, average monthly household income and location.

\section{“New Normal" Practices}

The participants were asked five questions to assess "new normal" practices, pertaining to wearing a mask, engaging in social distancing, avoiding physical contact with others, undergoing temperature screening and scanning a QR code before entering premises. The response options were very willing, willing, neutral, not willing and not at all willing.

\section{Economic and Social Disruption}

Questions on economic disruption (two items) asked the participants about any loss of family income and/or increased daily expenses following the COVID-19 pandemic. Questions on social disruption (two items) assessed disruptions to participants' connectedness with society and loved ones.

\section{Psychological Well-Being}

The Oxford Happiness Questionnaire is a scale that is used to measure psychological well-being. ${ }^{8}$ It was originally devised as a broad measure of personal happiness. The scale consists of 29 items and is scored using a six-point Likert scale response format, ranging from $1=$ strongly disagree to $6=$ strongly agree. Twelve items are reversescored from the total 29. The lowest possible sum of the item score is 29 and the highest is 174 . The score range is commonly interpreted as 1 to 6 (total score divided by 29), with a higher score on the scale indicating a greater level of happiness. In this study, the score was interpreted as 12 not happy, 2-3 somewhat unhappy, 3-4 not particularly happy or unhappy, 4 somewhat happy, 4-5 rather happy, 5-6 very happy, and 6 too happy. The average score of the Oxford Happiness Questionnaire is four. ${ }^{8}$ The participants were asked to rate both their current level of happiness and their happiness level before the COVID-19 pandemic in late December 2020. In this survey, the validated Chinese version of the Oxford Happiness Questionnaire was used. ${ }^{9}$ The Oxford Happiness Questionnaire has been used in studies from many countries globally such as in the US, UK, Australia, Canada, Italy and Iran. ${ }^{10-12}$ It has also been validated in studies conducted in China., ${ }^{9,13}$ The psychometric properties of the Oxford Happiness Questionnaire are well established and many studies found the Oxford Happiness Inventory to be a reliable and psychologically valid tool for assessing levels of happiness. ${ }^{12,14,15}$

\section{Statistical Analysis}

Differences between participants' current mean happiness score and mean happiness score before the COVID-19 pandemic were calculated using paired-sample $t$-test. We ran univariate analyses followed by multivariable logistic regression analysis, including all the factors showing significance $(\mathrm{p}<0.05)$ in the univariate analyses into the multivariable model, to determine the factors associated with the participants' current level of happiness (no $=$ score $<4$; yes $=$ score of $\geq 4$ ). Odds ratios (ORs), 95\% confidence intervals (95\% CIs) and $p$-values were calculated for each independent variable. The model fit of the multivariable logistic regression analysis was assessed using the Hosmer-Lemeshow goodness-of-fit test. ${ }^{16}$

\section{Results}

A total of 8393 complete responses were received. Table 1 shows the demographics of our study participants compared with the general adult population in China. ${ }^{17,18}$ The study received responses from participants from all regions of mainland China and representing diverse demographic groups. Being an online survey, numerous responses were received from respondents aged 18-25 years, even though this age group represents the lowest proportion of the total population in China. Table 1 also shows that the proportion of responses by region corresponded to the population's distribution across the country. 
Table I Comparison of Demographic Characteristics of the Study Population and the General Adults Population in China, 2018

\begin{tabular}{|c|c|c|c|}
\hline Characteristics & $\mathbf{N}$ & $\begin{array}{c}\text { \% Study } \\
\text { Population } \\
\mathrm{N}=8393\end{array}$ & 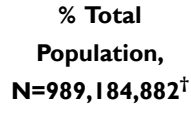 \\
\hline \multicolumn{4}{|l|}{ Age Group (Years) } \\
\hline $18-25$ & 2483 & 29.6 & $5.95^{\dagger}$ \\
\hline $26-35$ & 2459 & 29.3 & $16.26^{\dagger}$ \\
\hline $36-45$ & 1355 & 16.1 & $14.45^{\dagger}$ \\
\hline $46-70$ & 2096 & 25.0 & $34.23^{\dagger}$ \\
\hline \multicolumn{4}{|l|}{ Gender } \\
\hline Male & 5116 & 61.0 & 51.1 \\
\hline Female & 3277 & 39.0 & 48.9 \\
\hline \multicolumn{4}{|c|}{ Average Monthly } \\
\hline \multicolumn{4}{|c|}{ Household Income $(\mathrm{CNY})^{\ddagger}$} \\
\hline$<4000$ & 1430 & 17.0 & 56.5 \\
\hline 4000-9999 & 3438 & 41.0 & 27.1 \\
\hline $10,000-14,999$ & 2196 & 26.2 & 11.2 \\
\hline$\geq 15,000$ & 1329 & 15.8 & 5.2 \\
\hline \multicolumn{4}{|l|}{ Region $\pi$} \\
\hline North China & 2787 & 33.2 & 12.6 \\
\hline Northeast China & 651 & 7.8 & 7.8 \\
\hline East China & 2354 & 28.0 & 29.5 \\
\hline South Central China & 1971 & 23.5 & 28.4 \\
\hline Southwest China & 424 & 5.1 & 14.5 \\
\hline Northwest China & 206 & 2.5 & 7.4 \\
\hline
\end{tabular}

Notes: ${ }^{\dagger}$ Total number of adults 20 to 70 years of age according to China Statistical Yearbook of 2019. ${ }^{\prime \prime}{ }^{\ddagger}$ China household monthly income distribution. ${ }^{12}$ "Northern region (Beijing, Tianjin, Hebei, Shanxi, Inner Mongolia); Northeast China (Liaoning, Jilin, Heilongjiang); East region (Shanghai, Jiangsu, Zhejiang, Anhui, Fujian, Jiangxi, Shandong, Taiwan); Southern Central China (Hunan, Guangdong, Guangxi, Hainan, Hong Kong, Macao, Henan, Hubei); Southwest China (Chongqing, Sichuan, Guizhou, Yunnan, Tibet); Northwest China (Shaanxi, Gansu, Qinghai, Ningxia, Xinjiang).

Figure 2 presents a map of the geographical distribution of the responses of this study and the regional total number of confirmed cases of COVID-19 as of 15 October 2020, the last day of data collection. The study had a slight underrepresentation of responses from Hubei province, where the outbreak originated. The majority of respondents were from the North (33.2\%) and the East (28.0\%). A slightly higher proportion came from urban localities (62.1\%).

Figure 3 shows the responses regarding "new normal" practices. The highest proportions of not willing (20.2\%) and not at all willing (4.0\%) responses were reported in wearing a face mask. Moreover, $16.0 \%$ reported that they were not willing and $3.5 \%$ reported that were not at all willing to avoid physical contact. Table 2 shows the results of the multivariable logistic regression analysis of participants' demographic backgrounds influencing their willingness to practise the "new normal". Participants aged 18-30 years claimed to be significantly less willing to wear a face mask, engage in social distancing, avoid physical contact and carry out temperature screening than older age groups. Compared to their male counterparts, female participants expressed greater willingness to practise social distancing, avoid physical contact, carry out temperature screening and scan a QR code before entering premises. In terms of ethnic variations, Han Chinese expressed greater willingness to practise social distancing, avoid physical contact, undergo temperature screening and scan a QR code than non-Han Chinese. By educational level, participants with a university degree claimed to be less willing to wear a face mask than those of lower educational levels. Participants with a secondary school education and below claimed to be less willing to practise social distancing, avoid physical contact, undergo temperature screening and scan a QR code before entering premises. Across all the "new normal" practices included in the study, participants meeting the highest income level ( $C N Y \geq 15,000$ claimed to be less willing to practise the "new normal" than those of lower income levels. There were no significant differences in "new normal" practices according to participants' region of origin in the univariate analyses, hence not included in the multivariate models.

Figure 4 shows the proportion of responses regarding the economic and social disruptions caused by the pandemic. A total of $26.1 \%$ reported major effects and $31.8 \%$ moderate effects in regard to family income loss. Similarly, $20.6 \%$ reported a major effect and $32.5 \%$ a moderate effect in increased daily expenses as a result of the pandemic. Disruption to social connectedness was reported as a moderate effect by $30.0 \%$ and a major effect by $24.1 \%$ of the study participants. A slightly lower proportion reported a moderate effect $(27.2 \%)$ or a major effect $(19.8 \%)$ as regards disruption to connectedness with loved ones.

The participants rated their current mean $( \pm \mathrm{SD})$ happiness score $(110.45 \pm 17.55)$ slightly lower than the mean happiness score before $(111.12 \pm 17.83)$ the COVID-19 pandemic $(\mathrm{t}=-9.01, \mathrm{p}<0.001)$. In total, 2060 (24.5\%) participants reported a score $\geq 4$ within the range of 1-6 regarding their current level of happiness. The multivariable logistic regression analysis (Table 3) demonstrated that female has greater odds of higher happiness scores than males $(\mathrm{OR}=1.29,95 \% \mathrm{CI}$ 1.16-1.44). The Han Chinese had 1.45 times larger odds of higher happiness scores than non-Han Chinese (OR= 


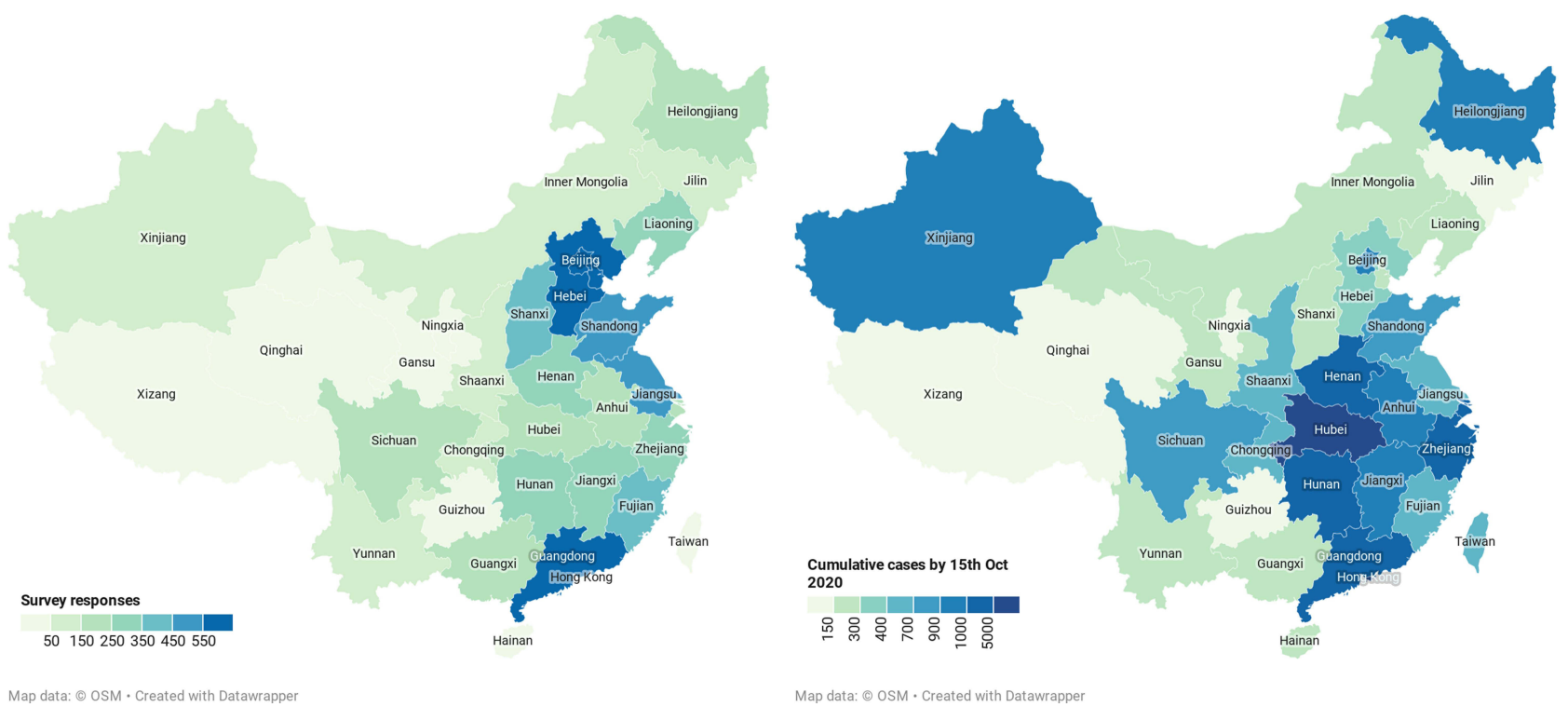

Figure 2 Geographical distribution of responses of the study and confirmed cases of COVID-19 as of I5th October 2020.

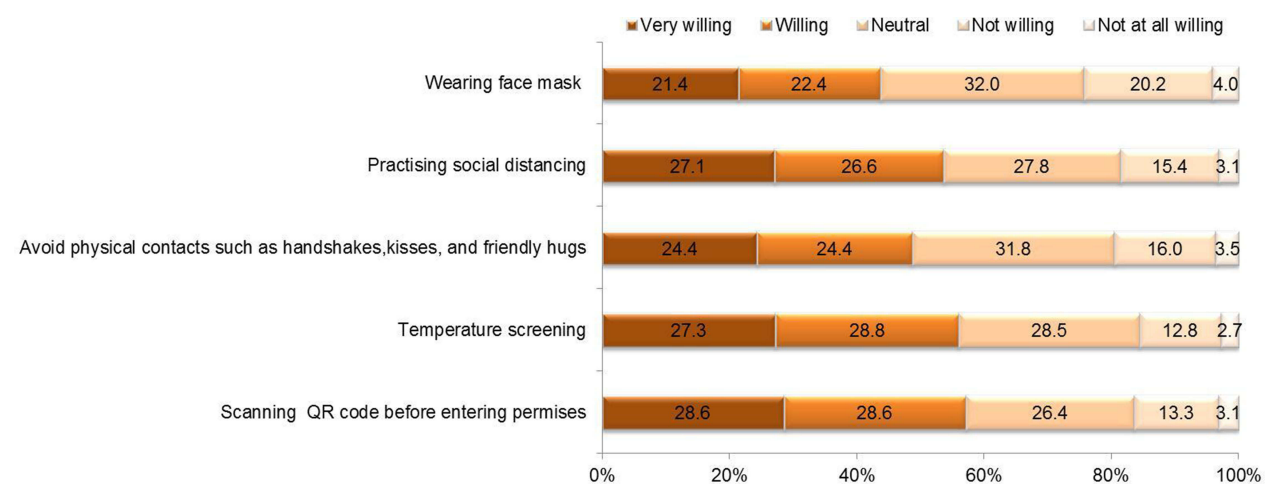

Figure 3 Proportion of responses for "new normal" practices items ( $N=8393)$.

$1.45,95 \%$ CI $1.20-1.74)$. There was a gradual increase in happiness scores with increased educational level and monthly household income. Participants from urban locations had significantly higher odds of happiness score $\geq 4$ than their rural counterparts. Greater willingness to practise the "new normal" was significantly associated with a higher current level of happiness. All the social disruption elements had a significant influence on people's levels of happiness in the univariate analyses. The multivariable logistic regression analysis revealed that having a lower effect in COVID-19related income losses $(\mathrm{OR}=1.18,95 \%$ CI $1.04-1.41)$ as well as interruptions in connectedness with loved ones $(\mathrm{OR}=1.42,95 \%$ CI $1.25-1.62)$ were associated with higher happiness scores.

\section{Discussion}

The study assessed the happiness level of the general public in China, comparing the level of happiness approximately 10 months after the novel coronavirus emerged in Wuhan with the level of happiness before the pandemic. Evidence of the influence in economic and social interactions on the level of happiness would aid the timely design and implementation of measures to rebuild the public's well-being towards a full recovery.

The fact that only about half of the participants claimed to be very willing or willing to practise all the recommend "new normal" practices is worrisome. Of particular concern, wearing a face mask was said to be the least willingly practised by the study participants, which has an important implication. The wearing of masks by the public 


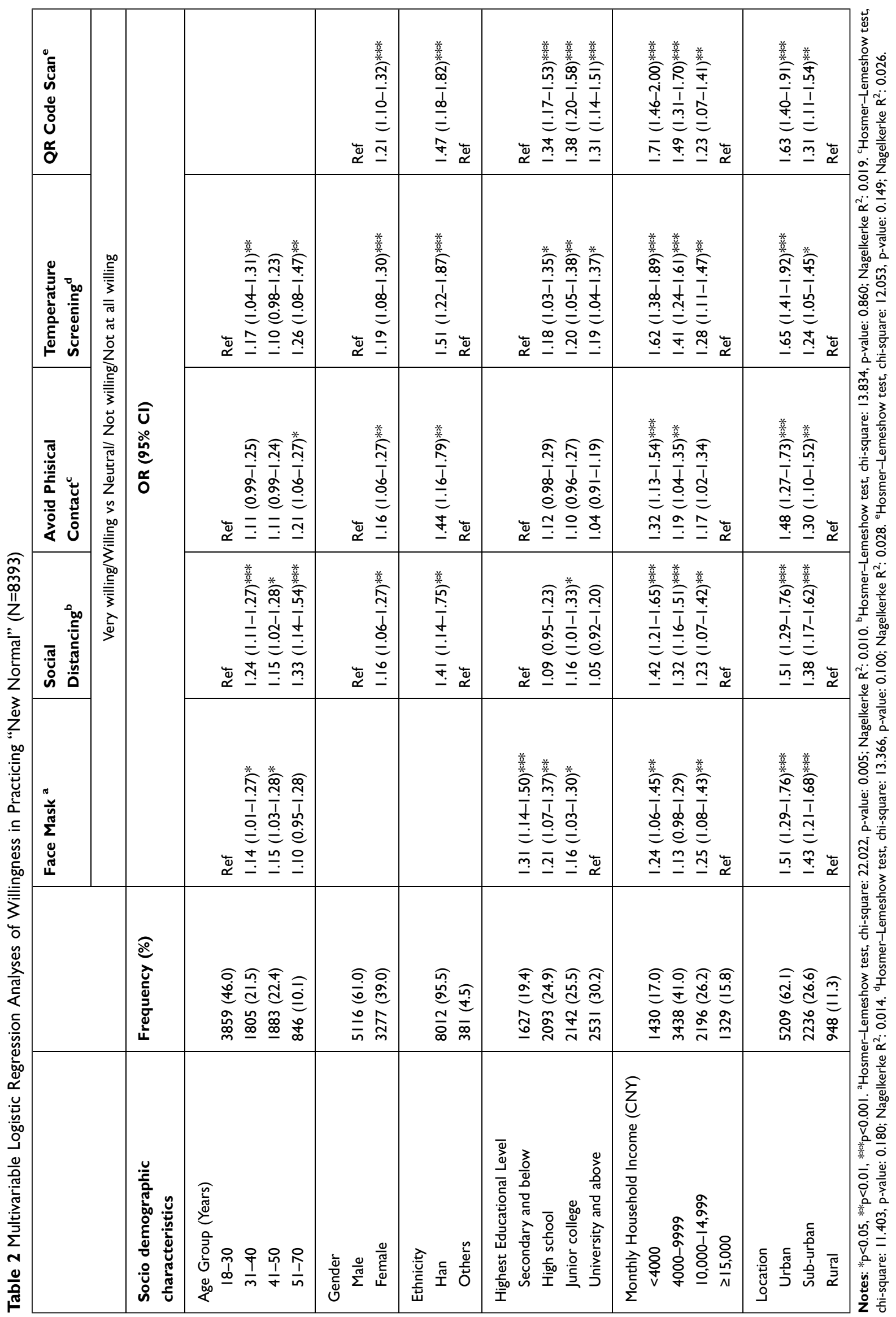




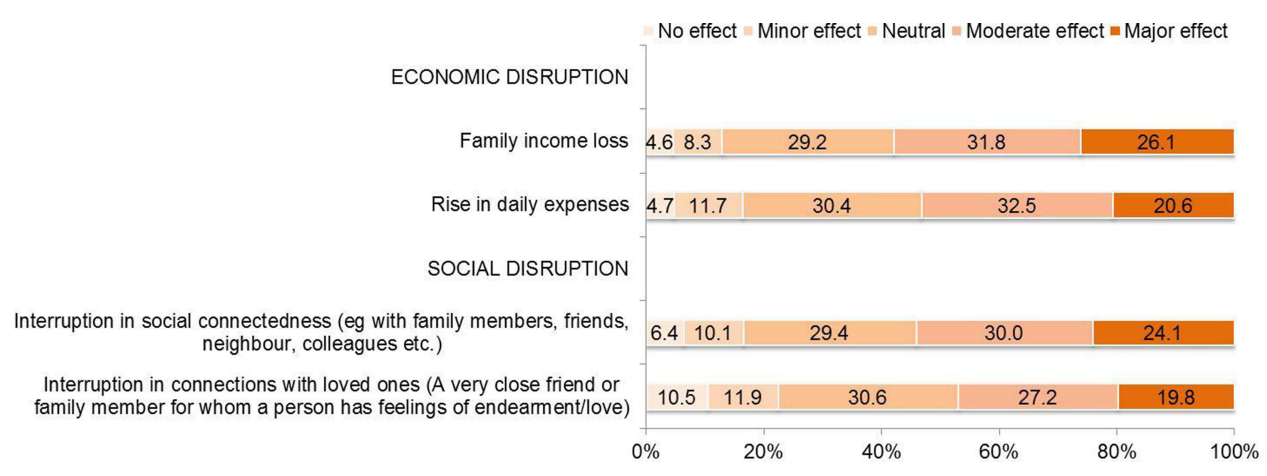

Figure 4 Proportion of responses for economic and social disruptions caused by the COVID-19 pandemic (N=8393).

during the COVID-19 pandemic has been highly recommended owing to evidence of these items' effectiveness in preventing the community transmission of SARS-CoV-2; thus, it has been suggested that the government should publicise the necessity of wearing face masks. ${ }^{19}$ The finding that the younger participants were less willing to adapt to "new normal" may be due to a perception that they are less susceptible to SARS-CoV-2, as has been recently reported in a study with young people in China. ${ }^{20}$ Most of the existing literature has reported that females are more likely than males to undertake preventive measures, ${ }^{21}$ as also found in this study. It is widely known that compared to women, men are more vulnerable to SARS-CoV-2 infection, ${ }^{22}$ hence dedicated behavioural intervention should be provided to the latter. People with a maximum of a secondary education expressed less willingness to engage in QR code scanning and temperature checks, perhaps due to a lack of digital literacy. This implies a need to increase the level of digital literacy among the general public with low levels of educational attainment. An interesting finding of this study was the decrease in willingness to wear a face mask with increased education. Participants with a university education or above reported the least willing to use a face mask. Also of note, the highest income groups $(\mathrm{CNY} \geq 15,000)$ were the least willing to adapt to the "new normal" practices. Further studies are warranted to investigate these associations. Urbanrural disparities in willingness should be considered when implementing health literacy promotion interventions.

Similarly, findings of approximately half of the respondents expressed a moderate or major effect in terms of economic and social disruptions in the post-pandemic "new normal" is worrisome. The pandemic has brought about fundamental changes in how people socialise and work and has led to a slowdown in economic activities in China and many other countries worldwide. ${ }^{23-25}$ Finding in regards to level of happiness of the public post-COVID -19 pandemic showed a slight decline in level of happiness among the general public in China compared to before the COVID-19 pandemic. In this study, the participants rated their current level of happiness slightly lower (110.45 \pm 17.55) than before the COVID-19 pandemic (111.12 \pm 17.83). Further, the mean current total happiness score in this study was higher than that reported in a previous study $(89.71 \pm 8.84)$ conducted with the public in China during the peak of the outbreak in January $2020 .{ }^{26}$ This finding implies that the psychological well-being of the public has returned to a normal level. A more recent report in early September 2020 noted that across China, people had returned to their normal work patterns and studies as well as social life, ${ }^{27}$ which may explain the resumed level of happiness among the study participants here.

The findings of the demographic disparities associated with greater happiness shed some light for policy makers in implementing targeted measures at groups that should be prioritised for support. The multivariable analysis suggested that those with low incomes and/or educational attainment, non-Han Chinese and people from rural locations should be the targets of psychological health interventions. Women around the world report higher levels of life satisfaction than men, ${ }^{28}$ a finding also obtained in this study. A gender gap in levels of happiness post-COVID-19 is a significant component of public health, as the wellbeing of men has important implications for their female partners and families. Identifying the issues linked to low levels of happiness among men is essential for the design and dissemination of targeted interventions to increase men's general well-being following the pandemic. 
Table 3 Factors Influencing Oxford Happiness Score (N=8393)

\begin{tabular}{|c|c|c|c|c|}
\hline \multirow[b]{2}{*}{ Socio demographic characteristics } & \multicolumn{3}{|c|}{ Univariable Analysis } & \multirow{2}{*}{$\begin{array}{l}\begin{array}{c}\text { Multivariable } \\
\text { Analysis }\end{array} \\
\text { Score } \geq 4 \text { vs score } \\
<4 \text { OR }(95 \% \mathrm{Cl})\end{array}$} \\
\hline & $\begin{array}{l}\text { Score } \geq 4 \\
(n=2060)\end{array}$ & $\begin{array}{l}\text { Score }<4 \\
(n=6333)\end{array}$ & p-value & \\
\hline $\begin{array}{l}\text { Age Group (Years) } \\
\qquad \begin{array}{l}18-30 \\
3 I-40 \\
4 I-50 \\
5 I-70\end{array}\end{array}$ & $\begin{array}{l}955(24.7) \\
422(23.4) \\
474(25.2) \\
209(24.7)\end{array}$ & $\begin{array}{l}2904(75.3) \\
1383(76.6) \\
1409(74.8) \\
637(75.3)\end{array}$ & 0.610 & \\
\hline $\begin{array}{l}\text { Gender } \\
\text { Male } \\
\text { Female }\end{array}$ & $\begin{array}{l}1135(22.2) \\
925(28.2)\end{array}$ & $\begin{array}{l}3981(77.8) \\
2352(71.8)\end{array}$ & $p<0.001$ & $\begin{array}{l}\text { Reference } \\
1.29(1.16-1.44)^{* * *}\end{array}$ \\
\hline $\begin{array}{l}\text { Ethnicity } \\
\qquad \text { Han } \\
\text { Others }\end{array}$ & $\begin{array}{l}1997(24.9) \\
63(16.5)\end{array}$ & $\begin{array}{l}6015(75.1) \\
318(83.5)\end{array}$ & $p<0.001$ & $\begin{array}{l}\text { I.45 (I.20-I.74)*** } \\
\text { Reference }\end{array}$ \\
\hline $\begin{array}{l}\text { Highest Educational Level } \\
\text { Secondary and below } \\
\text { High school } \\
\text { Junior college } \\
\text { University and above }\end{array}$ & $\begin{array}{l}218(13.4) \\
448(21.4) \\
582(27.2) \\
812(32.1)\end{array}$ & $\begin{array}{l}1409(86.6) \\
1645(78.6) \\
1560(72.8) \\
1719(67.9)\end{array}$ & $\mathrm{p}<0.001$ & $\begin{array}{l}\text { Reference } \\
\mathrm{I} .45(1.20-1.74)^{* * *} \\
\mathrm{I} .8 \mathrm{I}(\mathrm{I} .5 \mathrm{I}-2.18)^{* * *} \\
2.14(\mathrm{I} .78-2.57)^{* * *}\end{array}$ \\
\hline $\begin{array}{l}\text { Monthly Household Income (CNY) } \\
\quad<4000 \\
4000-9999 \\
10,000-14,999 \\
\geq 15,000\end{array}$ & $\begin{array}{l}225(15.7) \\
912(26.5) \\
559(25.5) \\
364(27.4)\end{array}$ & $\begin{array}{l}1205(84.3) \\
2526(73.5) \\
1637(74.5) \\
965(72.6)\end{array}$ & $p<0.001$ & $\begin{array}{l}\text { Reference } \\
1.68(1.42-2.00)^{* * *} \\
1.56(1.30-1.88)^{* * *} \\
I .78(1.46-2.18)^{* * *}\end{array}$ \\
\hline $\begin{array}{l}\text { Location } \\
\text { Urban } \\
\text { Sub-urban } \\
\text { Rural }\end{array}$ & $\begin{array}{l}1456(28.0) \\
466(20.8) \\
138(14.6)\end{array}$ & $\begin{array}{l}3753(72.0) \\
1770(79.2) \\
810(85.4)\end{array}$ & $p<0.001$ & $\begin{array}{l}\mathrm{I} .30(\mathrm{I} .06-\mathrm{I} .6 \mathrm{I})^{*} \\
\mathrm{I} . \mathrm{I} 3(0.9 \mathrm{I}-\mathrm{I} .4 \mathrm{I}) \\
\text { Reference }\end{array}$ \\
\hline $\begin{array}{l}\text { Region } \\
\text { North China } \\
\text { Northeast China } \\
\text { East China } \\
\text { South Central China } \\
\text { Southwest China } \\
\text { Northwest China }\end{array}$ & $\begin{array}{l}689(24.7) \\
173(26.6) \\
567(24.1) \\
468(23.7) \\
110(25.9) \\
53(25.7)\end{array}$ & $\begin{array}{l}2098(75.3) \\
478(73.4) \\
1787(75.9) \\
1503(76.3) \\
314(74.1) \\
153(74.3)\end{array}$ & 0.693 & \\
\hline New Normal Practices & & & & \\
\hline $\begin{array}{l}\text { Wearing Face Mask } \\
\text { Very willing/willing } \\
\text { Neutral/Not willing/Not at all willing }\end{array}$ & $\begin{array}{l}994(27.0) \\
1066(22.6)\end{array}$ & $\begin{array}{l}2885(73.0) \\
3648(77.4)\end{array}$ & $p<0.001$ & $\begin{array}{l}\text { I.I7 (I.03-1.34)* } \\
\text { Reference }\end{array}$ \\
\hline $\begin{array}{l}\text { Practising Social Distancing } \\
\text { Very willing/willing } \\
\text { Neutral/Not willing/Not at all willing }\end{array}$ & $\begin{array}{l}1303(28.9) \\
757(19.5)\end{array}$ & $\begin{array}{l}3199(71.1) \\
3134(80.5)\end{array}$ & $p<0.001$ & $\begin{array}{l}\text { I.I7 (I.0I-1.35)* } \\
\text { Reference }\end{array}$ \\
\hline
\end{tabular}

(Continued) 
Table 3 (Continued).

\begin{tabular}{|c|c|c|c|c|}
\hline \multirow[b]{2}{*}{$\begin{array}{l}\text { Avoid physical contacts such as handshakes, kisses, and friendly } \\
\text { hugs }\end{array}$} & \multicolumn{3}{|c|}{ Univariable Analysis } & \multirow{2}{*}{$\begin{array}{l}\text { Multivariable } \\
\text { Analysis }\end{array}$} \\
\hline & & & & \\
\hline Very willing/willing & $1167(28.5)$ & $2925(71.5)$ & $\mathrm{p}<0.001$ & $0.91(0.80-1.05)$ \\
\hline Neutral/Not willing/Not at all willing & $893(20.8)$ & $3408(79.2)$ & & Reference \\
\hline \multicolumn{5}{|l|}{ Temperature Screening, } \\
\hline Very willing/willing & 1445 (30.7) & $3260(69.3)$ & $\mathrm{p}<0.001$ & $1.52(1.31-1.75)^{* * *}$ \\
\hline Neutral/Not willing/Not at all willing & $615(16.7)$ & $3073(83.3)$ & & Reference \\
\hline \multicolumn{5}{|l|}{ Scanning QR code before entering permises } \\
\hline Very willing/willing & $1528(31.8)$ & $3270(68.2)$ & $\mathrm{P}<0.001$ & $2.26(1.97-2.60)^{* * *}$ \\
\hline Neutral/Not willing/Not at all willing & $532(14.8)$ & $3063(85.2)$ & & Reference \\
\hline \multicolumn{5}{|l|}{ Economic Disruption } \\
\hline \multicolumn{5}{|l|}{ Family Income Losses } \\
\hline Major/Moderate effect & $1066(21.9)$ & $3795(78.1)$ & $P<0.001$ & Reference \\
\hline Neutral/Minor/No effect & $994(28.1)$ & $2538(71.9)$ & & $1.18(I .04-1.4 I)^{* *}$ \\
\hline \multicolumn{5}{|l|}{ Rise in Daily Expenses } \\
\hline Major/Moderate effect & $1016(22.8)$ & $3444(77.2)$ & $\mathrm{P}<0.001$ & Reference \\
\hline Neutral/Minor/No effect & $1044(26.5)$ & $2889(73.5)$ & & $1.02(0.90-1.16)$ \\
\hline \multicolumn{5}{|l|}{ Social Disruption } \\
\hline \multicolumn{5}{|l|}{$\begin{array}{l}\text { Interruption in social connectedness (eg with family members, } \\
\text { friends, neighbour, colleagues etc.) }\end{array}$} \\
\hline Major/Moderate effect & $1026(22.6)$ & $3511(77.4)$ & $\mathrm{p}<0.001$ & Reference \\
\hline Neutral/Minor/No effect & $1034(26.8)$ & $2822(73.2)$ & & $1.04(0.91-1.18)$ \\
\hline \multicolumn{5}{|l|}{$\begin{array}{l}\text { Interruption in connections with loved ones (A very close friend } \\
\text { or family member for whom a person has feelings of } \\
\text { endearment/love) }\end{array}$} \\
\hline Major/Moderate effect & $822(20.8)$ & $3124(79.2)$ & $\mathrm{p}<0.001$ & Reference \\
\hline Neutral/Minor/No effect & $1238(27.8)$ & $3209(72.2)$ & & $1.42(1.25-1.62)^{* * *}$ \\
\hline
\end{tabular}

Notes: ${ }^{*} \mathrm{P}<0.05,{ }^{*} \mathrm{p}<0.01,{ }^{* * *} \mathrm{p}<0.001$. Hosmer-Lemeshow test, chi-square: 7.046, $\mathrm{p}$-value: 0.532 ; Nagelkerke $\mathrm{R}^{2}: 0.125$.

An important highlight of this study is the direct association observed between willingness to practise the "new normal" and level of happiness. Our findings indicate that positive behavioural tendencies and emotional well-being are interrelated. This again emphasises the importance of cultivating optimal well-being of the public to maintain the current low levels of community transmission in China. Further, the multivariate model uncovered that people who reported an interruption in their social connectedness with loved ones and who suffered income losses exhibited lower levels of happiness. Therefore, it is important to identify how the public in general are affected differently by the pandemic as well as by the postCOVID-19 restrictions. Lastly, efforts to reach out to the individuals and groups most in need of support are essential.
There are some limitations of the current study that need to be considered when interpreting the results. First, the use of an online survey may have resulted in sampling bias, so the results may not be generalisable to the wider community, as reflected in the lack of representation from some locations. In particular, response rate from the Southwest and Northwest regions were particularly lower that the estimated sample size. Second, the issue of selfreporting bias represents a key problem in the validity of the assessment. Thirdly, it should be noted that social and diseases or comorbidities related factors that could also potentially influence level of happiness were not measured in this study. The findings of this survey should be interpreted in light of the above-mentioned limitations. Despite 
these limitations, we believe that our findings contribute tremendously to understanding public responses to the post-COVID-19 era.

\section{Conclusion}

The revealed that quarantines during the COVID-19 pandemic along with the post-pandemic "new norms" have resulted in significant economic and social disruptions for nearly half of the general public in China. Findings have important implications for the government authorities in addressing the economic and social disruptions associated with the pandemic. This study has highlighted the need to encourage the public to embark on sustainable "new normal" practices and to incorporate them as a way of life and culture. The present study also uncovered quite a range of prevention practice gaps in the post-pandemic era that have never been reported in China, hence provides first-hand information to improve sustainability in COVID-19 prevention. The socialdemographic variations in willingness to adopt "new normal" practices identified by this study may provide insights for policy makers to plan for behavioural change interventions and to deliver targeted messages. Although levels of happiness have nearly returned to what they were before the pandemic, segments of the public continue to experience significant economic and social effects and the postpandemic "new norms" remain at risk of leading to psychological consequences. Tackling the psychological consequences impact in the vulnerable segment of the population is highly recommended.

\section{Abbreviation}

QR, Quick Response; ORs, Odds ratios; 95\% CIs, 95\% confidence intervals; CNY, Chinese Yuan; SD, standard deviation; SARS-CoV-2, severe acute respiratory syndrome coronavirus 2 .

\section{Data Sharing Statement}

The datasets used and/or analyzed during the current study are available from the corresponding author on reasonable request.

\section{Ethics Approval and Consent to Participate}

This study was approved by the Medical Ethics Committee at Fujian Medical University, Fuzhou, China. This study was conducted in accordance with the Declaration of Helsinki. Respondents were informed that their participation was voluntary, and consent was implied on the completion of the questionnaire.

\section{Author Contributions}

All authors made a significant contribution to the work reported, whether that is in the conception, study design, execution, acquisition of data, analysis and interpretation, or in all these areas; took part in drafting, revising or critically reviewing the article; gave final approval of the version to be published; have agreed on the journal to which the article has been submitted; and agree to be accountable for all aspects of the work.

\section{Funding}

This study was supported by the Pilot Project of the Fujian Provincial Department of Science and Technology [grant number 2020Y0005]; Clinical Medicine Center Construction Program of Fuzhou [grant number 2018080305]. The funders had no role in study design, data collection and analysis, decision to publish, or preparation of the manuscript.

\section{Disclosure}

The authors report no conflicts of interest in this work.

\section{References}

1. Scheid JL, Lupien SP, Ford GS, West SL. Physiological and psychological impact of face mask usage during the COVID-19 pandemic. Int J Environ Res Public Health. 2020;78(18):6655. doi:10.3390/ ijerph 17186655

2. Di Corrado D, Magnano P, Muzii B, et al. Effects of social distancing on psychological state and physical activity routines during the COVID-19 pandemic. Sport Sci Health. 2020;16:1-6. doi:10.1007/ s11332-020-00697-5.

3. Galea S, Merchant RM, Lurie N. The mental health consequences of COVID-19 and physical distancing: the need for prevention and early intervention. JJAMA Intern Med. 2020;180(6):817-818. doi:10.1001/ jamainternmed.2020.1562

4. Ren X, Huang W, Pan H, Huang T, Wang X, Ma Y. Mental health during the COVID-19 outbreak in China: a meta-analysis. Psychiatr Q. 2020;91(4):1033-1045. doi:10.1007/s11126-020-09796-5

5. Chen J, Lu H, Melino G, et al. COVID-19 infection: the China and Italy perspectives. Cell Death Dis. 2020;11(6):1-7. doi:10.1038/ s41419-020-2603-0

6. Yang H, Ma J. How an epidemic outbreak impacts happiness: factors that worsen (vs. protect) emotional well-being during the coronavirus pandemic. Psychiatry Res. 2020;289:113045. doi:10.1016/j. psychres.2020.113045

7. Zhou T, Nguyen TT, Zhong J, Liu J. A COVID-19 descriptive study of life after lockdown in Wuhan, China. $R$ Soc Open Sci. 2020;7 (9):200705. doi:10.1098/rsos.200705

8. Hills P, Argyle M. The oxford happiness questionnaire: a compact scale for the measurement of psychological well-being. Pers Individ Dif. 2002;33(7):1073-1082. doi:10.1016/S0191-8869(01)00213-6 
9. Li YA, Chen YL. Dimensional structure of oxford happiness questionnaire (Revision) and verification of its reliability and validity. Health Med Res Pract. 2013;10:34-41.

10. Bayani AA. Test-retest reliability, internal consistency, and construct validity of the farsi version of the oxford happiness inventory. Psychol Rep. 2008;103(1):139-144. doi:10.2466/pr0.103.1.139-144

11. Meleddu M, Guicciardi M, Scalas LF, Fadda D. Validation of an Italian version of the oxford happiness inventory in adolescence. $J$ Pers Assess. 2012;94(2):175-185. doi:10.1080/ 00223891.2011 .645931

12. Francis LJ, Brown LB, Lester D, Philipchalk R. Happiness as stable extraversion: a cross-cultural examination of the reliability and validity of the oxford happiness inventory among students in the UK, USA, Australia, and Canada. Pers Individ Dif. 1998;24(2):167-171. doi:10.1016/S0191-8869(97)00170-0

13. Lu L, Shih JB. Personality and happiness: is mental health a mediator? Pers Individ Dif. 1997;22(2):249-256. doi:10.1016/ S0191-8869(96)00187-0

14. Mousavi A, Sharafi Z, Mahmoudi A, Shahraki HR. Measurement invariance and psychometric analysis of oxford happiness inventory scale across gender and marital status. Biomed Res Int. 2020;2020:8906209. doi:10.1155/2020/8906209

15. Robbins M, Francis LJ, Edwards B. Happiness as stable extraversion: internal consistency reliability and construct validity of the oxford happiness questionnaire among undergraduate students. Curr Psychol. 2010;29(2):89-94. doi:10.1007/s12144-010-9076-8

16. Hosmer DW Jr, Lemeshow S, Sturdivant RX. Applied Logistic Regression. 3rd ed. John Wiley \& Sons; 2013. doi:10.1002/ 9781118548387

17. National Bureau of Statistics of China [homepage on the Internet]. 2019 China statistical yearbook; 2020. Available from: http://www. stats.gov.cn/tjsj/ndsj/2019/indexch.htm. Accessed November 15, 2020 .

18. JingLiang L. How much do we know about the income of Chinese people; 2020. Available from: https://iesr.jnu.edu.cn/2020/0610/ c17144a490625/page.htm. Accessed November 15, 2020.
19. Wang J, Pan L, Tang S, Ji JS, Shi X. Mask use during COVID-19: a risk adjusted strategy. Environ Pollut. 2020;266(Pt 1)):115099. doi:10.1016/j.envpol.2020.115099

20. Ding Y, Du X, Li Q, et al. Risk perception of coronavirus disease 2019 (COVID-19) and its related factors among college students in China during quarantine. PLoS One. 2020;15(8):e0237626. doi:10.1371/journal.pone.0237626

21. Guzek D, Skolmowska D, Głąbska D. Analysis of gender-dependent personal protective behaviors in a national sample: polish adolescents' COVID-19 experience (PLACE-19) study. Int J Environ Res Public Health. 2020;17(16):5770. doi:10.3390/ijerph17165770

22. Bwire GM. Coronavirus: why men are more vulnerable to covid-19 than women? SN Compr Clin Med. 2020;2:1-3. doi:10.1007/s42399020-00341-w

23. Jesus TS, Landry MD, Jacobs K. A 'new normal' following COVID19 and the economic crisis: using systems thinking to identify challenges and opportunities in disability, telework, and rehabilitation. Work. 2020;67(1):37-46. doi:10.3233/WOR-203250

24. Zeegen EN, Yates AJ, Jevsevar DS. After the COVID-19 pandemic: returning to normalcy or returning to a new normal? J Arthroplasty. 2020;35(7S):S37-S41. doi:10.1016/j.arth.2020.04.040

25. You S, Wang H, Zhang M, Song H, Xu X, Lai Y. Assessment of monthly economic losses in Wuhan under the lockdown against COVID-19. Humanit Soc Sci Commun. 2020;7(1):1-2. doi:10.1057/ s41599-020-00545-4

26. Li S, Wang Y, Xue J, Zhao N, Zhu T. The impact of COVID-19 epidemic declaration on psychological consequences: a study on active Weibo users. Int $J$ Environ Res Public Health. 2020;17 (6):2032. doi:10.3390/ijerph17062032

27. CGTN. Shed masks and party again: china moves on from COVID-19; 2020. Available from: https://news.cgtn.com/news/ 2020-09-07/Shed-masks-and-party-again-China-moves-on-fromCOVID-19-TB3v1knfBC/index.html. Accessed November 16, 2020.

28. Joshanloo M, Jovanović V. The relationship between gender and life satisfaction: analysis across demographic groups and global regions. Arch Womens Ment Health. 2019;1-8. doi:10.1007/s00737-01900998-w
Risk Management and Healthcare Policy

\section{Publish your work in this journal}

Risk Management and Healthcare Policy is an international, peerreviewed, open access journal focusing on all aspects of public health, policy, and preventative measures to promote good health and improve morbidity and mortality in the population. The journal welcomes submitted papers covering original research, basic science, clinical \& epidemiological studies, reviews and evaluations, guidelines, expert opinion and commentary, case reports and extended reports. The manuscript management system is completely online and includes a very quick and fair peer-review system, which is all easy to use. Visit http://www.dovepress.com/testimonials.php to read real quotes from published authors. 